\title{
O PODER DO DISCURSO NA INTERPRETAÇÃO
}

Christiano Sanches é professor na Formação em Interpretação de Conferências da Pontifícia Universidade Católica do Rio de Janeiro, sendo Mestre em Estudos da Linguagem pela mesma instituição. Atua como intérprete de conferências e tradutor, com os idiomas inglês, francês e português. E-mail: christianosanches@gmail.com

\section{Resumo}

O objetivo deste artigo é analisar a atuação do intérprete do ponto de vista do poder que ele detém como agente de comunicação que faz uso do discurso, sempre informado por suas referências políticas, ideológicas e pessoais. Dois casos são apresentados para ilustrar como a interpretação pode ser vista como exercício de poder, assim como para questionar os limites e as consequências de atuação dos intérpretes.

\begin{abstract}
This paper aims to analyze the task of the interpreter from the standpoint of the power he has as a communication agent who uses the discourse. Such use is always informed by the interpreter's political, ideological and personal background. Two cases are presented as instances where interpreting can be seen as an exercise of power, and also to question the limits and consequences of interpreting.
\end{abstract}

\section{1) Introdução}

Este $\operatorname{artigo}^{1}$ procura responder a uma demanda dos Estudos da Interpretação, ou seja, a de abordar um tema que permanece sub-representado quando comparado ao conjunto de produções científicas e acadêmicas da área: o poder.

Tal sub-representação é sustentada pela opinião de autores como Michael Cronin (2002), que enfatiza a necessidade de se aumentar a representação de pesquisas sobre interpretação que abordem temas ligados a poder ou ideologia, seguindo o rumo já tomado pelos Estudos da Tradução. Uma das preocupações de Cronin é justamente a ideia de que a questão do controle seria o "problema central da tradução em geral e da interpretação em particular" (p. 392) e que, portanto, precisa ser investigada.

Além disso, encontra-se nos Estudos da Interpretação uma recorrência da imagem do intérprete como intermediário que ocupa um "entre-lugar", espaço desconectado do contexto no qual estão inseridos os usuários da interpretação. A esse respeito, autores como Franz Pöchhacker (2004) criticam a imagem generalizada de um intérprete "não-pessoa", máquina invisível de tradução ocupando uma posição neutra entre interlocutores. Tal crítica ao posicionamento do intérprete levou Mona Baker (2010) a rever a abordagem mais recorrente nos Estudos da Interpretação e observar o intérprete como inserido em uma narrativa, a qual, por sua vez, seria parte de outras tantas narrativas, não oferecendo a possibilidade de uma exterioridade, de um "entrelugar".

As opiniões mencionadas acima representam um movimento de "virada cultural" aplicado à interpretação (Cronin, 2002), herdada dos Estudos da Tradução, que vê a atividade dos intérpretes como inserida em contextos sociais, políticos e culturais que informam a atuação dos mesmos.

No âmbito deste trabalho, o poder é concebido como capacidade de agir, como agentividade, ou seja, "a capacidade socialmente determinada de agir e fazer a

\footnotetext{
${ }^{1}$ Artigo produzido a partir de dissertação de mestrado do autor. Ver: SILVA, C. e MARTINS, M., 2013.
} 
diferença" (BARKER, 2012, p. 498), diretamente ligada ao ato de escolher, à escolha da palavra e/ou equivalente linguístico mais adequado, de acordo com o contexto e segundo o critério de cada profissional. Daí a importância de pensarmos no que informa cada escolha e tantas variações, um arcabouço que podemos chamar de ideologia, ou conjunto de valores e normas que servem de referencial para a realização de qualquer ação.

Como veremos a seguir, a ideologia é parte integrante da linguagem e o discurso, uma forma de poder. Ambos são o instrumento primeiro do trabalho do intérprete, a matéria que ele procura receber e transmitir, mas não sem antes transformar.

Dois casos são apresentados ao final deste artigo, transpondo para a concretude de situações reais a reflexão aqui apresentada.

\section{2) Discurso e poder}

Em sua obra $O$ Poder Simbólico, Bourdieu (2003) desenvolve uma abordagem social e política do poder em diferentes níveis. Seu texto nos remete à ideia de que o poder se encontra onde é menos visto, onde é simbólico. Tal simbolismo estaria presente não só na arte, na religião, mas também, e especialmente, na língua, nas relações de comunicação, que seriam sempre relações de poder, dependendo, "na forma e no conteúdo, do poder material ou simbólico acumulado pelos agentes (ou pelas instituições) envolvidos nessa relação" (BOURDIEU, 2003, p. 11).

Os sistemas simbólicos, como vê Bourdieu, funcionariam de maneira a reforçar sua própria legitimidade, o que seria feito através da modulação do próprio discurso, do uso da palavra.

O que faz o poder das palavras e das palavras de ordem, poder de manter a ordem ou de subvertê-la, é a crença na legitimidade das palavras e daquele que as pronuncia, crença cuja produção não é da competência das palavras. (BOURDIEU, 2003, p. 15) ${ }^{2}$

A importância do discurso, como sistema simbólico detentor de poder, também é salientada por Foucault (2011). Em sua aula inaugural no Collège de France, em 2 de dezembro de 1970, publicada sob o título de A Ordem do Discurso, o autor nos fala da

inquietação de sentir sob essa atividade [o discurso], todavia cotidiana e cinzenta, poderes e perigos que mal se imagina; inquietação de supor lutas, vitórias, ferimentos, dominações, servidões, através de tantas palavras cujo uso há tanto tempo reduziu as asperidades. (FOUCAULT, 2011, p. 8)

Foucault (2011) desenvolve a visão de uma sociedade na qual o discurso é controlado e exerce um papel central em mecanismos de exclusão e de interdição. Além disso, mesmo que o discurso aparente ser pouca coisa, "as interdições que o atingem revelam logo, rapidamente, sua ligação com o desejo e o poder" (p. 10). E continua no

\footnotetext{
${ }^{2}$ Esta e todas as demais traduções presentes neste artigo são de autoria do autor deste trabalho.
} 
aprofundamento dessa relação colocando o discurso não na posição de instrumento de reprodução ou difusão do poder, mas naquela do próprio poder. Em suas palavras:

[...] o discurso não é simplesmente aquilo que traduz as lutas ou os sistemas de dominação, mas aquilo por que, pelo que se luta, o poder do qual nos queremos apropriar. (FOUCAULT, 2011, p. 10)

O discurso deixa de ocupar o lugar daquilo que expressa um desejo e passa ao lugar do próprio objeto de desejo.

Na mesma linha, Chabry et Chabry (2003) apresentam, em Le pouvoir dans tous ces états, uma visão da evolução do pensamento sobre o poder. Originalmente circunscrito à ciência política, o poder atrai aos poucos um olhar mais diversificado, deixando de ser uma instância puramente jurídica e passando a ser visto como atuante e mesmo estruturante - nas relações sociais. Ele não é mais algo exercido por um único indivíduo ou por uma única instituição, mas passa a ser visto no lugar que ocupa nos diversos níveis de relacionamento entre indivíduos e instituições. Além disso, o poder deixa de ser apenas considerado como uma ação específica, ou o resultado dela, na qual alguém obtém algo concreto. Observa-se uma subjetividade, uma não explicitação muito mais insidiosa do que aquilo que é visível.

Os autores concluem o primeiro capítulo da obra, "Le concept de pouvoir", com a seguinte constatação:

[...] fomos levados a constatar que toda teoria do poder apoia-se necessariamente - mas nem sempre explicitamente - sobre um postulado que diz respeito à natureza da relação entre o ator político e seu ambiente, entre aquilo que é concebido muitas vezes como uma "interioridade" (a subjetividade) e uma "exterioridade" (o real) [...] (CHABRY \& CHABRY, 2003, p. 22)

Aprofundando o tema, Foucault (1996) procura desenvolver uma "genealogia" de um poder descentralizado. Para ele, não se pode mais atribuir o poder apenas ao Estado, que seria a única entidade a exercê-lo. O poder do Estado só existe, na verdade, baseado em toda uma complexa rede de relações que o alimentam, em um meio social construído e moldado por relações de poder das quais ninguém está isento. Como explica Roberto Machado, na introdução ao livro A Microfísica do Poder (1996), a maneira de ver de Foucault convoca uma forma de análise que não seja mais de cima para baixo, do centro para a periferia. O olhar de Foucault pretende partir do detalhe, do micro, entender suas especificidades e, só então, compreender como todos os pontos se ligam a uma forma de poder central ou hegemônico. Nas palavras de Machado, surge, com Foucault, a necessidade de uma nova abordagem nos estudos sobre o poder:

[...] a necessidade de utilizar uma démarche inversa: partir da especificidade da questão colocada, que para a genealogia que ele tem realizado é a dos mecanismos e técnicas infinitesimais de poder que estão intimamente relacionados com a produção de determinados saberes - sobre o criminoso, a sexualidade, a doença, a loucura, etc. - e analisar como esses micropoderes, que possuem tecnologia e história específicas, se 
relacionam com o nível mais geral do poder constituído pelo aparelho do Estado. (MACHADO, 1996, p. XIII-XIV)

Essa breve reflexão sobre discurso e poder, alimentada pelo pensamento filosófico, é o ponto de partida para uma tentativa de compreender como a interpretação (seja ela de conferências, comunitária, de tribunal, em língua de sinais, ou outra), se configura como exercício de poder.

Contudo, pensar o discurso como poder exige que se investigue a relação da estrutura do discurso com o poder. Portanto, é preciso compreender o papel da própria linguagem, matéria prima do discurso. Para tal, recorre-se aqui ao que nos propõe a linguística antropológica.

\section{3) Ideologia na linguagem}

A linguística antropológica ${ }^{3}$ desenvolveu uma abordagem conhecida como Ideologia da Linguagem. Esse campo de pesquisas procura denotar a influência ideológica na própria estrutura da linguagem, nas normas que definem aquilo que é adequado ou não e que assim contribuem para a estratificação social dos falantes de acordo com o uso que fazem da língua.

Michael Silverstein (1979), por exemplo, em seu artigo intitulado "Language Structure and Linguistic Ideology", começa por fazer referência às definições de dicionário, que procuram assumir o papel de autoridade no estabelecimento do sentido correto das palavras com base em pressupostos que estão ligados a todo um arcabouço ideológico, a um modelo linguístico específico. O autor associa a escolha baseada em dicionários com uma ideologia norte-americana que, por si só, já informaria o uso que se faz da linguagem. Diz ele:

Se eu começasse com a observação "o dicionário Webster define ideologia como...", vocês teriam um exemplo de uma ideologia linguística americana muito comum em ação. Seria o apelo retórico ao dicionário publicado como autoridade codificada sobre aquilo que as palavras realmente significam. Até mesmo a força arbitrária dessa retórica baseia-se num amplo conjunto de racionalizações sobre a natureza da autoridade do dicionário em tais questões. (SILVERSTEIN, 1979, p. 193)

Da mesma maneira, Silverstein (1979) argumenta que, ao buscarmos a origem etimológica de determinada palavra, temos a ilustração de "outra proposta ideológica comum sobre o significado 'verdadeiro', ou até mesmo central das palavras com base em suas origens etimológicas" (p. 193). Conhecimento este que, de alguma forma, nos permitiria usar as palavras com correção. O que o autor nos leva a perceber, é que, qualquer que seja a escolha que façamos, ela será necessariamente informada por algum pressuposto, por algum conjunto de ideias e conceitos que a validam.

\footnotetext{
${ }^{3}$ A linguística antropológica nasceu como ramificação da antropologia que se preocupava em estudar e listar línguas ameaçadas de desaparecimento. Na sua aplicação moderna, a linguística antropológica teve o caminho aberto por Michael Silverstein, aluno de Roman Jakobson, em estudos dedicados à questão das ideologias da linguagem.
} 
Para Silverstein (1979), “ideologias da linguagem, ou ideologias linguísticas, são quaisquer conjuntos de crenças sobre linguagem articulados pelos usuários como racionalização ou justificação da estrutura e do uso percebidos da linguagem" (p. 193). Em palestra proferida em 2006, Jan Blommaert retoma Silverstein e resume: "ideologias da linguagem são crenças, ideias, visões e percepções sobre linguagem e comunicação" (p. 2).

Segundo Blommaert (2006), a abordagem das ideologias da linguagem nos permite investigar os fenômenos sociolinguísticos "não como dados, mas como construídos em realidades situadas" (p. 2). Parte dessas "realidades situadas" seria invisível, porém presente na forma de padrões que permitiriam um grau de coletividade no uso que é feito da linguagem. Esses "complexos ideacionais pertencem a todos os aspectos da comunicação: das formas e funções linguísticas até arcabouços comportamentais mais amplos (muitas vezes chamados de 'não linguísticos') nos quais ocorrem" (p. 2).

Assim, ainda de acordo com Blommaert (2006), a linguagem seria apenas um modo de produção de sentido e as pessoas seriam vistas como "realizando" (performing) significados, pois a própria estrutura de sua fala já denotaria uma série de referências socioculturais e contextuais, independentemente do sentido mais exteriorizado do discurso produzido.

Como diz Silverstein (1979), a relação entre ideologia e a própria estrutura da linguagem "seria a mesma que se verifica em qualquer outra esfera da vida social, um fenômeno de grande significação para a prática da linguística" (p. 193).

Ao analisar o campo de investigação das ideologias da linguagem, na introdução da obra "Language Ideologies", Kathrin Woolard (1998) esclarece que a expressão ideologia da linguagem significa as "representações, sejam explícitas ou implícitas, que constroem a intersecção da linguagem e dos seres humanos num mundo social" (p. 3). Segundo a autora, as ideologias da linguagem não dizem respeito apenas à linguagem em si, mas aos laços existentes entre linguagem e temas como identidade, estética, moralidade e epistemologia.

Através de tais vínculos, [as ideologias da linguagem] subjazem não somente a forma linguística, mas também a própria noção da pessoa e do grupo social, assim como instituições sociais fundamentais como o ritual religioso, as relações de gênero, o estado nação, a educação e a lei. (WOOLARD, 1998, p. 3)

Woolard (1998) menciona o trabalho de Silverstein e o conceito de metapragmática por ele utilizado, que envolveria um "comentário implícito e explícito sobre a linguagem em uso e sinalizações a seu respeito" (p. 4).

Para entendermos um pouco de que maneira essas investigações sobre ideologias da linguagem fazem sentido na prática do dia-a-dia, ou seja, no uso da linguagem, apresentamos um exemplo mencionado por Blommaert (2006) que ilustra a ideia de Silverstein de que uma forma específica representaria um significado social e cultural específico: 
Assim, em francês, tu e vous partilham uma boa quantidade de significado linguístico, mas são diferenciados por significados indéxicos: $t u$ indexa um interlocutor "inferior" de segunda pessoa do singular, enquanto vous indexa um interlocutor de segunda pessoa do singular "superior". Aquele que utiliza tu ou vous expressaria indexicamente o seu grau de respeito e distanciamento social com relação ao interlocutor, e o interlocutor atribuiria características de identidade convencionais, tais como "cordial", "adequado", "bem educado", "classe média", etc. àquele que utiliza essas formas. (BLOMMAERT, 2006, p. 2-3)

Fica mais fácil, a partir do exemplo acima, entender a importância de um intérprete saber se utilizará vocês, ou os senhores, ou as senhoras e os senhores, quando um determinado palestrante de língua inglesa disser simplesmente you ao dirigir-se ao público presente. Essa escolha, que vai além de uma simples concordância de número, que pode facilmente ser resolvida pela observação da quantidade de interlocutores presentes, seria um exemplo do que a ideologia da linguagem, entre tantos outros fatores, procura observar. A partir dessa escolha aparentemente simples, fica determinado não somente o nível de relação que o intérprete quer manter com seus ouvintes, parecendo mais ou menos formal, mais ou menos culto, mas também o nível de relação que ele atribui ao falante principal na relação com seus interlocutores, ou com seu público. Na experiência profissional, percebemos que existe uma série de situações nas quais o código social pressupõe a utilização de um registro mais formal, e que a opção pelo você em uma dessas circunstâncias seria vista, não somente pelos ouvintes como também pelos colegas de trabalho, como um desvio da norma e, portanto, uma falha profissional.

Mesmo sem termos a intenção de exaurir a discussão no campo da ideologia linguística, podemos, como quer Woolard (1998), perceber "a inevitável relevância de sua dimensão" (p. 4) para estudos que envolvam ideologia e discurso de maneira geral. Além disso, para a autora, embora haja muitos pontos de divergência entre os estudos na área, os artigos publicados a respeito "compartilham de uma ênfase fundamental nas origens sociais do pensamento e da representação, em suas raízes oriundas da experiência particular de uma posição social ou sua responsividade a tais experiências" (WOOLARD, 1998, p. 10).

Os aspectos ideológicos presentes no uso e estrutura da linguagem podem também ser percebidos hoje no que Blommaert (2006) chama de "comoditização da linguagem". Em um ambiente globalmente dominado pelo inglês como língua dos negócios, vemos cada vez mais uma ênfase em aspectos menos centrais do idioma, do ponto de vista linguístico, sendo exibidos como uma vantagem pela qual se deve pagar. No caso, o autor menciona a importância que cursos de idioma atribuem ao sotaque e como fica aparente o seu caráter de estratificação social:

Não basta produzir sentenças gramaticalmente bem formadas em inglês, deve-se produzir essas sentenças com um sotaque de Michigan ou de Illinois. Os fornecedores de tais cursos de idioma não são nada discretos com relação ao que está em jogo: em um mundo globalizado, você não quer apenas falar inglês. Você quer falar inglês americano, ou ainda mais precisamente, você quer soar como o americano médio (do 
meio-oeste, classe média). Não surpreende que ainda estejamos por encontrar um fornecedor que tente vender um sotaque nigeriano, ou paquistanês. A comodificação do sotaque não é uma questão de uniformização, mas de estratificação da crescente diversidade do campo do inglês. (BLOMMAERT, 2006, p. 6)

A questão aqui, segundo Blommaert (2006), é que essa comercialização de aspectos linguísticos se dá a partir da ativação de imagens ideológicas de função, sugerindo, no caso apresentado acima, que um idioma como o inglês deve ser falado com um sotaque "neutro", que não identifique o falante como tendo uma origem precisa, mas sim como um cidadão global. Não agir desta forma seria permanecer "local, ou seja, reconhecível como sendo originário de algum lugar como a Nigéria ou o Paquistão (ou a Bélgica, a África do Sul, o Brasil, etc.)” (p. 6-7).

Assim, percebemos como tanto a forma da linguagem quanto a estrutura social são mediadas por ideologias linguísticas, e o estudo de tais ideologias permitiria uma melhor compreensão de como esses aspectos interagem entre si, de como se informam mutuamente. Para Blommaert (2006), o tipo de poder que se exerce a partir da interação entre ideologia, linguagem e estrutura social é um "poder capilar, aquele que Foucault descreveu como produtor de pessoas como sujeitos que agem num tópico de maneira específica, sistemática e, desta forma, tornam-se alguém" (p. 7).

A relevância das leituras da ideologia linguística para este trabalho é exatamente mostrar o quanto os aspectos ideológicos encontram-se presentes desde a própria estrutura da linguagem, ajudando-nos a perceber até que ponto é importante abordar esse tema ao se falar de interpretação.

\section{4) Poder e ideologia nos Estudos da Interpretação}

O questionamento ligado à ideologia e ao poder na interpretação tem se concentrado principalmente em torno da análise do papel do intérprete em contextos específicos. Ele seria visto como um intermediário, um elo de comunicação entre interlocutores de culturas diferentes, com pesos distintos.

$\mathrm{Na}$ descrição das funções do intérprete, muito se levou em conta a atividade em sua modalidade simultânea, mediada pela tecnologia. Assim, a imagem de neutralidade e invisibilidade do intérprete ganhou força, com prescrições de precisão, completude e fidelidade na elocução e rejeição a qualquer iniciativa discursiva por parte do intérprete, definido como "uma 'não-pessoa' ocupando uma posição neutra entre os interlocutores" (PÖCHHACKER, 2004, p. 147).

Dessa visão resultou uma concepção generalizada de que o intérprete atuaria como uma máquina invisível de tradução entre uma língua A e outra B. Essa visão mecanicista foi reforçada pela exigência de literalidade extrema do contexto jurídico, no qual o discurso indireto não pode ser considerado como evidência, devendo o intérprete abster-se de qualquer "interferência" no discurso traduzido, por menor que seja (PÖCHHACKER, 2004).

Ainda com relação ao papel do intérprete profissional, seu desempenho foi estudado em diferentes contextos com base nas expectativas de usuários de 
interpretação no que diz respeito ao grau de interferência ativa do intérprete e em seu papel de mediador cultural, devendo o intérprete, ou não, acrescentar suas próprias explicações para elucidar questões de diferenças culturais.

Basicamente, as pesquisas ficaram concentradas na definição, ou compreensão, dos limites da atuação do intérprete, levando-se em conta os diferentes contextos possíveis de sua prática (interpretação comunitária, médica, jurídica, simultânea, em língua de sinais, etc.). A partir da análise do papel do intérprete e suas limitações/possibilidades, visivelmente calcada numa necessidade de definição desse papel, procurou-se observar critérios de profissionalismo e ética, vinculados ao grau de envolvimento do profissional como participante ativo na interação entre os usuários da interpretação. Tais observações levaram à constatação de situações nas quais existe uma sobrecarga, ou um conflito de funções do intérprete, demonstrando que seu desempenho não é pautado apenas por uma questão de profissionalismo, mas que "a amplitude e o poder exercidos pelos intérpretes ao realizar suas funções estão sujeitos a limitações específicas de contexto nos níveis interacional, socioprofissional e institucional" (PÖCHHACKER, 2004, p. 153).

Há trabalhos sobre interpretação que abordam temas ligados a ideologia ou a poder, contudo, como já foi dito na introdução deste artigo, segundo Cronin (2002), esse tipo de pesquisa ainda está sub-representado. Além disso, grande parte do material produzido na área de interpretação comunitária preocupa-se com questões de treinamento, certificação e dificuldades práticas com as quais os intérpretes lidam (PÖCHHACKER, 2004).

Além do papel de mediador já mencionado anteriormente, Cronin (2002) resgata a imagem do intérprete como uma criatura monstruosa, vivendo entre dois mundos e inspirando tanto admiração quanto desconfiança e desprezo, sentimentos opostos causados pelo desejo de se estar próximo ao intérprete, pela vontade de manipulá-lo e pelo medo de ser enganado por ele.

\section{5) O intérprete mediador?}

Quanto à ideia de que tradutores e intérpretes podem ser considerados mediadores entre interlocutores ou culturas diferentes, existem autores que discordam dessa abordagem e que preferem não utilizar o conceito de mediador, ou de alguém que se posiciona num espaço entre dois lados opostos.

Mona Baker considera mediação como "um desses termos que é usado em toda parte, mas que raramente é definido" (BAKER, 2008, p. 15), sendo, contudo, comumente associado ao trabalho do tradutor/intérprete.

Da mesma forma, Maria Tymoczko (2003) argumenta que o uso do discurso do “entre-lugar" é enganador e não ajuda na compreensão do envolvimento ideológico dos profissionais da área. Para a autora, os estudos da tradução tenderam, recentemente, a considerar o tradutor como ocupando um espaço desconectado de sua realidade física, assim como de seu arcabouço ideológico. Esse lugar da tradução tampouco estaria ligado à cultura fonte, ou à cultura meta. 
Para Tymoczko (2003), a atribuição desse espaço intermediário aos tradutores em geral estaria ligada a um aspecto da interpretação, quando esta acontece no modo consecutivo e o intérprete se posiciona fisicamente entre os interlocutores. Contudo, esta seria uma concepção arquetípica e idealizada, generalizada tanto para tradução quanto para interpretação. Se essa generalização já não é adequada para todos os modos de interpretação, é ainda mais distante da tradução escrita, que nem assume esse tipo de configuração espacial. Além disso, o conceito de espaço intermediário favorece a desconexão da figura do tradutor de tudo aquilo que diz respeito ao seu contexto de atuação e seu universo interno de valores, elementos que marcam sua maneira de atuar.

Para evitar essa armadilha conceitual, Baker (2010) optou por entender a tradução e a interpretação como narrativas, que seriam estórias contadas a nós mesmos ou a outros que orientam nossa maneira de agir e nosso comportamento, estando relacionadas a outras narrativas ou a contextos mais amplos que envolvem uma determinada narrativa.

Narrativas, nessa visão, são "histórias" públicas e pessoais às quais aderimos e que orientam nosso comportamento. São as histórias que contamos a nós mesmos, não apenas aquelas que explicitamente contamos a outros, sobre o mundo, ou mundos nos quais vivemos. Como resultado, a narrativa, no sentido da teoria social, não remete necessariamente a um trecho específico de texto, sustentando, mais provavelmente, toda uma gama de textos e discursos sem que necessariamente esteja total ou explicitamente articulada em nenhum deles. (BAKER, 2010, p. 1)

Segundo a autora, "a teoria narrativa não permite 'espaços intermediários': ninguém, nem mesmo os tradutores, pode estar fora das narrativas ou entre elas" (BAKER, 2010, p. 8). De acordo com esta abordagem, o papel de tradutores e intérpretes seria visto no centro das interações, "nas narrativas que moldam suas próprias vidas, assim como as vidas daqueles para quem traduzem e interpretam" (p. 89), numa teia da qual todos fazem parte e para a qual todos contribuem.

Baker procura encorajar uma prática e um estudo da tradução que sejam mais engajados politicamente, e vê no momento histórico atual uma justificativa forte para essa postura:

Isto é particularmente importante neste ponto da história, quando tradutores e intérpretes estão fortemente envolvidos na mediação de uma variedade de conflitos políticos violentos, tornando-se eles próprios alvos de morte e prisão, quando alguns tradutores participaram da tortura de prisioneiros em locais como Abu Ghraib (ver e.g. Zernike 2004), e quando um número crescente de tradutores e intérpretes profissionais estão se unindo para formar grupos determinados a utilizar suas capacidades linguísticas para realizar mudanças políticas. Penso aqui em grupos como Babels, ECOS e Tlaxcala, entre outros. (CHESTERMAN \& BAKER, 2008, p. 12)

Outro autor que contesta a utilização da ideia de que intérpretes atuariam a partir de um "entre mundos" é Franz Pöchhacker (2006). Em seu artigo "Interpreters and ideology: from between to within", o autor analisa exatamente a tendência mais recente 
a se ver o intérprete como parte integrante da ação e não mais como intocado pelas interações do contexto no qual atua.

Sendo ele próprio membro da comunidade de intérpretes, pode afirmar com propriedade como os profissionais da área tipicamente se consideram além do alcance de ideologias específicas, ou entre elas, o que parece ser um posicionamento que caracteriza a prática profissional, assim como suas raízes conceituais. Essa posição de intermediário estaria ainda ligada ao conceito essencial à atividade, o de imparcialidade - aqui entendido como um grau atenuado de neutralidade -- segundo o qual os intérpretes não participariam das intenções ou ações de nenhuma das partes comunicantes, caracterizando a "noção de imparcialidade, e até mesmo de neutralidade, como pedra angular da profissão de intérprete" (PÖCHHACKER, 2006, p. 193).

Para Pöchhacker (2006), a discussão sobre interpretação e ideologia poderia ser mais aprofundada ao nos distanciarmos da "visão de que intérpretes estariam posicionados de maneira mais ou menos imparcial entre ideologias e ao reconhecermos seu papel no interior de sistemas e instituições sociopolíticos" (p. 199). Além disso, atividades essenciais ao trabalho de interpretação, como o processamento conceitual e a organização lógica, que permitem distinguir aquilo que é importante do que não tem tanta importância, "não são possíveis fora de uma perspectiva de classe e independentemente de uma visão político-ideológica básica" (KADE, 1963, p. 15 apud PÖCHAHACKER, 2006, p. 200).

Posicionar-se entre ou no interior pode ser fundamental e, às vezes, perigoso para intérpretes que trabalhem em zonas de conflito armado, contudo, Pöchhacker (2006) salienta que mesmo se desconsiderarmos essas situações de conflito armado, o tema do envolvimento dos intérpretes e do ponto de vista ideológico tornou-se importante na prática da profissão em geral (p. 10).

Propõem-se, em seguida, a análise de dois contextos diferentes de interpretação sob a ótica das discussões apresentadas acima.

\section{6) Caso 1: Interpretação comunitária em situações de asilo político}

Tradução e interpretação na comunicação mundial desempenham papel chave em situações tornadas ainda mais numerosas pela globalização atual. Um exemplo típico e, talvez, extremo, é o contexto de asilo político. Robert Barsky (1996) investigou as pressões e restrições institucionais que cerceiam o discurso tanto dos agentes de imigração quanto daqueles que solicitam asilo político (apud INGHILLERI, 2009, p. $11)^{4}$. A pesquisa de Barsky utilizou arquivos de audiências de Convention Refugees ${ }^{5}$ canadenses, examinando de que forma restrições tanto institucionais quanto discursivas afetavam a capacidade de solicitantes e de agentes de imigração de chegar a um

\footnotetext{
${ }^{4}$ BARSKY, R. F. The Interpreter as Intercultural Agent in Convention Refugee Hearings. The Translator. Vol. 2, n. 1, 1996. p. 45-63.

${ }^{5}$ Convention Refugees são aqueles que se enquadram nas definições publicadas pela Alto Comissariado das Nações Unidas para Refugiados, em sua Convenção e Protocolo de 1951. O Canadá é um dos países signatários da convenção e utiliza tais diretrizes na análise de pedidos de refugiados que desejam obter o direito de residir no país.
} 
entendimento mais nuançado em termos culturais. Para Inghilleri (2009) a pesquisa de Barsky sugere que "os solicitantes de asilo estavam sobrecarregados pela tarefa de projetar uma imagem pessoal através de suas narrativas que coincidisse com as expectativas das autoridades de imigração" (p. 11). Resulta dessa constatação a sugestão oferecida por Barsky de encorajar os intérpretes a agir como "agentes interculturais e intermediários ativos entre os solicitantes e o serviço de imigração para compensar as lacunas tanto culturais quanto linguísticas na compreensão" (INGHILLERI, 2009, p. 11).

O mesmo contexto é explorado, como relata Inghilleri (2009), por Blommaert $(2001)^{6}$ e Maryns (2006) ${ }^{7}$, numa abordagem sociolinguística, verificando como a especificidade do discurso dos requerentes de asilo era, por assim dizer, anulada por um “arcabouço institucional generalizável” (INGHILLERI, 2009, p. 11), no qual ficava negada a possibilidade de relatos culturalmente localizados, mais personalizados, por parte dos requerentes.

Percebemos aqui o reconhecimento de limitações no estabelecimento da comunicação entre idiomas e culturas diferentes, o que leva a uma extrapolação do papel do intérprete - que de mediador linguístico passaria a agir, caso atendida a sugestão de Barsky (1996), como agente social ativo com atribuições outras que não a pura e simples tradução linguística, nos moldes do que ocorria na antiguidade, quando se chegou a falar de "intérpretes diplomatas", com atribuições outras que não as de caráter exclusivamente linguístico.

Mesmo que não aceitem essa nova incumbência, os intérpretes já são, nessa pesquisa, vistos como profissionais que desempenham "um papel na institucionalização de narrativas culturalmente específicas, localmente derivadas" (INGHILLERI, 2009, p.11), pois, através de seu trabalho, contribuem para a construção de narrativas dos solicitantes de asilo que estejam de acordo com o paradigma do contexto burocrático no qual são avaliados.

O exemplo é ainda mais contundente quando se esclarece que, no caso de refugiados kosovares, os intérpretes, também originários do Kosovo, recebiam a função de "avaliar a credibilidade do pedido de um solicitante, distinguindo falantes da variante gheg do albanês falado no Kosovo daquele falado no norte da Albânia" (INGHILLERI, 2009, p. 11), para que nenhum albanês não kosovar passasse despercebido pelo serviço de concessão de asilo. Daí a conclusão da pesquisa de que "o papel dos intérpretes foi transformado no de detetives de comunicação" (p. 11).

Observa-se que a posição assumida pelos intérpretes em determinado contexto de forças os leva a uma produção discursiva que não desafia a autoridade local instituída, mas reforça-a - mesmo que de maneira nem sempre consciente no caso dos funcionários do departamento de Convention Refugees - a partir do momento em que os intérpretes constroem sua identidade profissional no interior de uma identidade institucional que os ultrapassa e assimila. Essa mesma identidade institucional também

\footnotetext{
${ }^{6}$ BLOMMAERT, J. Investigating Narrative Inequality: African Asylum Seekers' Stories in Belgium. Discourse and Society. Vol. 12, n. 4, p. 413-49.

${ }^{7}$ MARYNS, K. The Asylum Speaker: Language in the Belgian Asylum Procedure. Manchester: St. Jerome, 2006.
} 
assimila o discurso do solicitante de asilo, despersonalizando-o e encaixando sua fala nos moldes dos mecanismos burocráticos governamentais.

Por outro lado, poderíamos também considerar que o posicionamento dos intérpretes é por si só uma escolha que reforça a instituição para a qual trabalham, numa construção mútua. Não se pode negar ao intérprete sua capacidade de escolher, ele não é uma massa amorfa que será moldada de acordo com cada contexto em que atue. Sendo assim, na busca natural pela inserção em um contexto profissional, nada impede que o intérprete se identifique com o discurso institucional do qual passa a ser uma peça chave, pois também precisa dele e, dessa forma, acolhe-o em seu funcionamento sistêmico. Uma relação de simbiose seria talvez o apropriado para descrever o que se passa em muitos desses casos. Além disso, a identificação com o discurso institucional serve a um propósito: para uns, proteção contra os excessos de um governo autoritário, para outros, quem sabe, garantia de que haverá mais trabalho no futuro, de que fazem parte da identidade da pátria que os acolheu, de que falam a mesma língua daqueles que, em determinada situação, detêm algum tipo de poder.

$\mathrm{O}$ caso das entrevistas de concessão de asilo também traz à tona algo que se tornou em muitos países uma prática "oficialmente sancionada", ou seja, a de utilizar intérpretes "na condução de identificação linguística para determinar a nacionalidade dos solicitantes de asilo" (INGHILLERI, 2009, p. 11), prática que se opõe ao processo de construção de confiança entre o intérprete e seus ouvintes, mencionado por David Bellos (2011a), visto que elimina completamente a presunção de imparcialidade e fere o código de conduta profissional de qualquer associação de intérpretes, demonstrando assim o uso abertamente ideológico/político da mediação, seja ela interpretação ou tradução. Nos trechos apresentados abaixo, pode-se ver a recomendação de que o intérprete não exerça nenhuma outra função que não a de intérprete de conferências, nos eventos em que atue como tal, no caso da Associação Internacional de Intérpretes de Conferência (AIIC), e de que seu trabalho seja exercido de maneira imparcial e não tendenciosa, não permitindo que opiniões pessoais interfiram em seu dever profissional, como encontrado no código de ética de uma empresa privada de serviços de interpretação:

Código de Ética Profissional da Associação Internacional de Intérpretes de Conferência:

Article 7

With a view to ensuring the best quality interpretation, members of the Association:

h) shall not perform any other duties except that of conference interpreter at conferences for which they have been taken on as interpreters.

(Disponível em: http://aiic.net/page/54. Grifo nosso)

Código de ética de uma empresa privada que oferece serviços de interpretação: 
IMPARTIALITY The interpreter shall be impartial and unbiased and shall refrain from conduct that may give an appearance of bias. He/she shall not allow personal opinions to interfere with his/her duties nor add unsolicited comments or make recommendations except to assist communication.

(Disponível em: <http://www.languageline.com/code_of_ethics>. Grifo nosso)

Segundo Inghilleri (2009), é preciso levar em conta que as entrevistas de solicitação de asilo costumam ocorrer "dentro de um clima de políticas nacionais e internacionais de exclusão que restringem de maneira significativa o direito de refugiados e solicitantes de asilo a serem adequadamente ouvidos" (p. 12). Por outro lado, a observação da estrutura de tais entrevistas revela o papel central que a interpretação e a tradução desempenham quando se pretende ampliar os direitos dos solicitantes a participar de um diálogo pela melhoria das políticas globais de asilo por meio do "desenvolvimento de concepções expandidas dos direitos humanos e normas transnacionais" (p. 12) que contribuam para esse fim.

Nesse contexto, fica claro como o discurso - e, mais ainda, o discurso interpretado/traduzido - pode ser usado como moeda de troca em níveis diversos: na relação entre solicitantes de asilo e autoridades locais, onde uns procuram comunicar sua elegibilidade e outros tentam verificar a autenticidade dos argumentos apresentados, assim como na relação entre intérpretes e instituição, na qual ambos estabelecem um acordo com base na escolha de um padrão de linguagem e comunicação (adequado à instituição) que, se respeitado, franqueia ao intérprete o acesso a uma estrutura e uma identidade por ele valorizadas. Além disso, como vimos, muitas vezes se espera do intérprete um trabalho de detetive da linguagem, função que ultrapassa as atribuições da interpretação pura e simples, denotando o papel específico que tais profissionais podem assumir ao se identificarem com uma instituição e seus objetivos.

$\mathrm{Na}$ configuração que se estabelece entre solicitantes, intérpretes e autoridades de imigração, as últimas seriam, à primeira vista, as mais fortes. Contudo, ao observarmos de perto o percurso pelo qual passa o discurso, tanto em um sentido quanto em outro, não é difícil perceber a possibilidade de influência que detêm os intérpretes, em outras palavras, seu poder.

\section{7) Caso 2: Interpretação em língua de sinais na Ucrânia}

Em outro exemplo, uma intérprete de língua de sinais interpreta, em cadeia nacional de televisão, o recém-eleito presidente da Ucrânia, em 2004.

A intérprete, a serviço do canal de televisão estatal UT-1, foi designada para interpretar em língua de sinais o discurso de posse do presidente eleito Viktor Yanukovych. Contudo, existiam indícios de que as eleições haviam sido fraudulentas, a população já se manifestava em praça pública e a intérprete, assim como outros cidadãos ucranianos, afirmou estar insatisfeita com o desenrolar dos fatos (ZARAKHOVICH, 2005).

Numa atitude coerente com suas convicções pessoais e políticas, Dmitruk resolveu não reproduzir em língua de sinais as palavras de Yanukovych, transmitindo, 
ao invés disso, a mensagem de que Yushchenko era o presidente eleito de fato pelo voto popular.

Yushchenko é nosso presidente. Não acreditem no Comitê Eleitoral Central.

Eles estão mentindo. (ZARAKHOVICH, 2005)

Um público de estimados cem mil portadores de deficiência auditiva recebeu a notícia, assim como jornalistas da rede de TV estatal, que aderiram ao movimento em prol da verdade. De maneira inédita no país, a iniciativa da intérprete de língua de sinais permitiu que toda a nação soubesse quem havia sido o presidente verdadeiramente eleito, tendo este seu direito restituído, e, no dia de seu discurso de posse, Viktor Yuschenko pediu ao canal UT-1 que Dmitruk fosse responsável pela interpretação em língua de sinais.

Mais tarde, a intérprete foi parabenizada por sua coragem durante um encontro em prol dos direitos humanos realizado nos Estados Unidos e para o qual foi convidada. Ao lhe perguntarem se faria tudo novamente, respondeu:

Se eu o faria de novo? Não, nunca", diz Dmitruk, admitindo que, apesar de moralmente justificado, o que fez foi uma violação das políticas da empresa. "Se lamento ter feito o que fiz? Nem um pouco, nem lamentarei jamais. Valeu a pena. (ZARAKHOVICH, 2005. Grifo nosso)

Como vemos no caso de Dmitruk, sua interferência direta no discurso original não era prevista. Como ela própria admitiu, seu gesto foi além das prerrogativas de sua função como intérprete.

Neste caso, a ética profissional deu lugar a uma ética da responsabilidade, semelhante à mencionada por Maria Clara C. de Oliveira (2008), uma ética que se aplica à ação política, mas que pode permear outras instâncias da vida, pois está relacionada às convicções político-ideológicas de cada um, que não podem ser separadas, por exemplo, da atuação profissional. O que ocorre é que essas convicções, em benefício da tão desejada imparcialidade, são normalmente deixadas de lado, temporariamente suprimidas, mas não eliminadas por completo.

Deparada com uma situação na qual suas convicções foram colocadas à prova, Dmitruk fez uma opção, uma opção política, consciente de que estava desrespeitando as normas da profissão. Evidentemente, trata-se de um caso excepcional, mas que nos lembra do quanto o intérprete possui seus próprios valores e tem a necessária independência para aplicá-los da maneira que julgar mais adequada.

Pensando pelo viés da fidelidade, podemos dizer que a intérprete de língua de sinais foi fiel a seus próprios valores, à sua nação ou povo, resultando no abandono do discurso fonte e na veiculação de outra mensagem que expressava apenas suas próprias convicções.

O caso ucraniano é também um exemplo da importância de se deter e controlar o discurso como expressão de poder. Retomando o que foi dito no início deste artigo, podemos pensar no poder simbólico de Bourdieu (2003), no qual as palavras de ordem 
têm a origem de sua força na "crença na legitimidade das palavras e daquele que as pronuncia, crença cuja produção não é da competência das palavras" (p. 15). A própria situação de um discurso de posse é em si um ritual de validação, de legitimação de poder, do qual o discurso é peça chave. Quando Dmitruk decide desviar-se completamente daquilo que estava sendo dito pelo orador, o presidente supostamente eleito, subverteu os parâmetros deste ritual, questionando diretamente sua validade e o poder com o qual sua principal figura fora investido. $O$ pacto de silêncio e consentimento foi quebrado, o que levou a uma reação popular. Em outras palavras, o momento de falar pela primeira vez à nação é carregado de simbolismo para aquele que assume o papel de representante de um país, de seu povo. O presidente eleito passa a ser, de certa forma, a voz da nação. Contudo, ao recorrer à interpretação para se comunicar com uma parcela dos cidadãos, o chefe de estado confiou no desempenho da intérprete, acreditando que ela se absteria de interferir no conteúdo de sua fala. No entanto, devido às suas convicções políticas e pessoais, a intérprete fez exatamente o contrário e trouxe à luz aquilo que mais se teme ao pensarmos em interpretação: a possibilidade de alteração do discurso original no momento em que este precisa passar pelo "canal" do intérprete. A voz do presidente não chegou ao público que fez uso da interpretação, mas sim, outra mensagem. A atitude da intérprete, que reconheceu ter extrapolado os limites de sua profissão, levou-a a ser homenageada em um evento internacional a favor da democracia, num uso claramente político da repercussão que sua atitude gerou e que enfatiza, mais uma vez, o valor ideológico do discurso.

Tudo isso só foi possível porque se tratava de interpretação em língua de sinais, linguagem desconhecida pelo principal envolvido, Yanukovych, que não tinha como saber o que a intérprete comunicava paralelamente ao seu discurso.

Pode-se, neste caso, pensar na linguagem como um recurso fundamental, um instrumento de ação, uma ação em si mesma que acarreta consequências e possui um valor intrínseco do qual querem se apropriar os agentes do poder em geral, como diria Foucault (2011), o que pode ser observado na influência mais explícita sobre o próprio conteúdo simbólico do discurso, como mencionado acima.

\section{8) Considerações finais}

Com base nas discussões aqui apresentadas, sobre a natureza do poder e sua relação íntima com a linguagem e com o discurso, sobre a construção ideológica da linguagem e sobre a participação ativa do intérprete em relações de comunicação, podemos compreender melhor até que ponto se faz necessário conhecer, e reconhecer, as repercussões do conteúdo ideológico presente em atos de comunicação. Somente assim, seremos capazes de determinar a medida da influência, ou poder, que detêm aqueles que participam do ato comunicativo.

Toda essa atenção ao gesto de um intérprete só reforça a ideia de que é de fato importante tratar com mais cuidado os conteúdos ideológicos na profissão, suas ligações com o exercício de poder e os resultados do mesmo. Interpretar implica, necessariamente, escolher, processar, transformar. Como vimos, todos esses atos podem ir, e com frequência vão, além do meramente linguístico. Ou, se assim preferirmos, 
podemos pensar que o linguístico é, por natureza, impregnado de ideologia, estruturado por ela. Portanto, como ignorar tal dimensão ao pensarmos a interpretação - e não somente ela - em um mundo no qual contatos entre culturas e idiomas se fazem cada vez mais frequentes e assumem formas cada vez mais diversas? Nesse sentido, muito mais há, nos Estudos da Interpretação, a ser explorado e este artigo pretende trazer uma contribuição a mais para o campo.

\section{Referências}

AIIC's Code of Professional Ethics. Disponível em: <http://aiic.net/page/54>. Acesso em: 28/06/2012.

BAKER, Mona. Ethics of Renarration: Mona Baker is interviewed by Andrew Chesterman. CULTUS, v.1, n.1, p. 10-33, 2008.

Narratives of terrorism and security: 'accurate' translations, suspicious frames. Critical studies on terrorism, v.3, n.3, p. 347-364, 2010.

BARKER, Chris. Cultural Studies: Theory and Practice. London: SAGE, 2012.

BELLOS, David. Is that a fish in your ear? Translation and the meaning of everything. London: Penguin Books, 2011.

BLOMMAERT, Jan. Language Ideologies and Power. Palestra proferida na International Sociology Conference, Durban, 27 Julho de 2006.

BOURDIEU, Pierre. O Poder Simbólico. Rio de Janeiro: Bertrand Brasil, 2003.

CHABRY, Annie; CHABRY Laurent. Le Pouvoir dans tous ses États: pour une nouvelle science politique. Paris: Imago, 2003.

CRONIN, Michael. The empire talks back: Orality, heteronomy and the cultural turn in interpreting studies. In: PÖCHHACKER, Franz; SCHLESINGER, Miriam (Orgs.). The Interpreting Studies Reader. London and New York: Routledge, 2002. p. 387-397.

FOUCAULT, Michel. Verdade e Poder. In: MACHADO, Roberto (Org.). Microfísica do Poder, Rio de Janeiro: Graal, 1996. p. 1-14.

A Ordem do Discurso: aula inaugural no Collège de France, pronunciada em 2 de dezembro de 1970. São Paulo: Edições Loyola, 2011.

INGHILLERI, Moira. Asylum. In: BAKER, Mona \& SALDANHA, Gabriela (Org.). Routledge Encyclopedia of Translation Studies. Londres e Nova Iorque: Routledge, 2009. p. 10-13. 
LLS. Language Line Services: Interpreter Code of Ethics. Disponível em: <http://www.languageline.com/code_of_ethics>. Acesso em: 25/08/2014.

OLIVEIRA, Maria Clara Castellões de. A tradução e a ética da responsabilidade em períodos ditatoriais. In: Seminário do GEL, v. 56, 2008, Programação... São José do Rio Preto (SP): GEL, 2008. Disponível em: http://www.gel.org.br/?mesa=22-08. Acesso em: 22/06/2011.

PÖCHHACKER, Franz. Introducing Interpreting Studies. Londres e Nova Iorque: Routledge, 2004.

SILVA, Christiano; MARTINS, Marcia. Questões de poder e ideologia nos estudos e na prática da interpretação. 2013. 87 f. Dissertação (Mestrado) - Pontifícia Universidade Católica do Rio de Janeiro, Departamento de Letras, 2013.

SILVERSTEIN, M. Language Structure and Linguistic Ideology. In: CLYNE, P., HANKS, W, \& HOFBAUER, C. (Org.). The Elements: A parassession on linguistic units and levels. University of Chicago, Illinois, 1979, p. 193-247.

TYMOCZKO, María. Ideology and the Position of the Translator: In What Sense is a Translator "In Between"?. In: PÉREZ, María Calzada (Ed.): Apropos of Ideology Translation Studies on Ideology - Ideologies in Translations, Manchester: St Jerome Publishing, 2003, p. 181-201.

WOOLARD, Kathryn A.. Language Ideology as a Field of Inquiry. In: SCHIEFFELIN, B. B., WOOLARD, K. A. e KROSKRYTI, P. V.. Language Ideologies. Practice and Theory, New York: Oxford University Press, 1998, p. 3-47.

ZARAKHOVICH, Yuri. Signs of the Times. Time Europe. 10 out. 2005. Disponível em: <http://www.time.com/time/magazine/article/0,9171,1112801,00.html>. Acesso em: 22/02/2012. 